\title{
Taenia solium metacestode immunodominant peptides recognized by IgG antibodies in cerebrospinal fluid and serum paired samples from patients with active and inactive neurocysticercosis
}

\author{
Ivanildes Solange da Costa Barcelos, Leandro Pajuaba de Moura*, \\ Vinicius Paulino da Costa ${ }^{*}$, Marcelo Simão Ferreira ${ }^{*}$, Julia Maria Costa-Cruz/ ${ }^{+}$ \\ Laboratório de Parasitologia, Instituto de Ciências Biomédicas *Departamento de Clínica Médica, Faculdade de Medicina, \\ Universidade Federal de Uberlândia, Av. Pará 1720, 38400-902 Uberlândia, MG, Brasil
}

The aim of this study was to test if serological distinction between patients with active and inactive neurocysticercosis (NCC), could be accomplished by the recognition of immunodominant peptides in total saline antigenic extract of Taenia solium metacestodes by IgG antibody in cerebrospinal fluid (CSF) and serum paired samples. CSF and serum samples of 10 each, active NCC patients, inactive NCC, and individuals with other neurological disorders, were used to recognize the antigenic peptides by western blot (WB). In the active NCC the 28-32 and 39-42 kDa peptides were more frequently detected in CSF than in sera ( $<<0.05)$. The 4752, 64-68, and $70 \mathrm{kDa}$ antigens showed high frequencies in both samples from patients with active NCC. All the CSF samples of inactive NCC and other neurological disorder (control) patients tested negative, while serum samples from these last two groups recognized mainly the 80, 86, 95, and $98 \mathrm{kDa}$ bands. This finding eliminates the use of the high molecular weigh bands $(\geq 80 \mathrm{kDa})$ for diagnosis of NCC. The final conclusions were that the difference between active and inactive NCC may be done with the detection of peptides only in the CSF samples and that the 47-52, 64-68, and $70 \mathrm{kDa}$ bands may be included as specific markers for active NCC when detected in CSF samples by WB using total saline extract of $\mathrm{T}$. solium metacestode.

Key words: IgG antibodies - neurocysticercosis - peptides - western blot

The life cycle of Taenia solium is complex and involves swine as intermediate hosts and humans as accidental hosts, only human are definitive hosts because their lodge the adult form in the small intestine. Neurocysticercosis (NCC) is the most common neuroparasitosis in the world. Frequently the symptoms are late onset epilepsy, intracranial hypertension, and mental disorders (Del Brutto 1999, Carpio 2002).

The diagnosis of NCC is given by the combined analysis of clinical data, neuroimaging (NI), computerized tomography (CT), and magnetic resonance imaging (MRI), as well as immunological and epidemiological data (Garcia et al. 2005). From NI findings of NCC, only the presence of cystic lesions demonstrating the scolex should be considered pathognomonic (Del Brutto et al. 2001). In epidemiological studies however, NI are unsuitable due to cost and time, being case definition based on methods of immunodiagnosis (Flisser et al. 2003). According to the immune-inflammatory response detected in the cerebrospinal fluid (CSF) or NI data suggestive of metacestodes, NCC can be classified as active or inactive. In the first case there is vesicular, colloidal or/and granular stages of degenerating parasites surrounded by a strong inflammatory reaction in the adjacent cerebral tissue (Sotelo et al. 1985, Sotelo \& Del

\footnotetext{
Financial support: $\mathrm{CNPq}$

+Corresponding author: costacruz@ufu.br

Received 27 February 2007

Accepted 9 July 2007
}

Brutto, 2000). Using histological and immunohistochemical methods, Alvarez et al. (2002) demonstrated that cells from granulomatous lesions in CNS during chronic NCC have cytotoxic activity, immunomodulation, and tissular repair functions. In inactive NCC patients have only calcified lesions with a mean diameter of $2 \mathrm{~mm}$ as measured by NI, with minimal immune response (Sotelo et al. 1985, Salgado et al. 1997, Sotelo $\&$ Del Brutto 2000).

As one of the diagnostic approaches for NCC, the immunologic tests more commonly used to detect antibodies against $T$. solium are the enzyme-linked immunosorbent assay (ELISA) and western blot (WB) in the CSF and/or serum (Montero et al. 2003, Barcelos et al. 2005, Schantz 2006). Using purified glycoproteins by enzyme-linked immunoelectrotransfer blot (EITB), Tsang et al. (1989) found high sensitivity and specificity indexes in serum and CSF samples. The IgG intrathecal synthesis and specific antibody index in patients with NCC can be documented using the formula of Reiber and Felgenhauer (1987) as performed by Machado et al. (2002).

The aim of this study was to make a serological distinction between patients with active and inactive NCC, based on the differential recognition of immunodominant peptides from $T$. solium crude metacestode extracts by IgG antibodies in CSF and serum paired samples.

\section{MATERIALS AND METHODS}

Patients and paired samples - This study was conducted according to the ethical guidelines of the Brazilian Health Ministry after being approved by the Research Ethics Committee of Universidade Federal de Uberlândia (UFU), Minas Gerais, Brazil. 
CSF and serum paired samples were obtained from the Biological Sample Collection of the Parasitology Laboratory at UFU, which were from 30 patients admitted to the General Hospital of UFU. These patients were classified into three groups: G1 - active NCC (10 patients with parenchimal cysts, $80 \%$ of them with multiple lesions: 1 patient with vesicular associated to inflammatory colloidal stage, 4 patients with inflammatory colloidal associated to nodular stage, and 3 patients with vesicular associated to granular stage. The other $20 \%$ presented only one cyst at inflammatory colloidal vesicular stage, as evaluated by NI); G2 - inactive NCC (10 patients with highly suggestive NCC, all of which had multiple parenchimal lesions in the calcified stage, as observed by NI); and G3 - the control group (10 patients who had other neurologic disorders with normal $\mathrm{NI}$ and negative for NCC in CSF samples by ELISA).

Parasites and preparation of saline extract - $T$. solium metacestodes were obtained from the muscles of naturally infected pigs. The saline extract was prepared as described by Costa et al. (1982) with modifications, briefly 50 metacestodes were disrupted in $5 \mathrm{ml}$ of distillated water and homogenized using a glass tissue homogenizer at $4^{\circ} \mathrm{C}$ for $5 \mathrm{~min}$. The metacestodes were then submitted to four sonication cycles in an ice bath at $40 \mathrm{kHz}$ during $30 \mathrm{~s}$ each, then $5 \mathrm{ml}$ of $\mathrm{NaCl} 0.3 \mathrm{M}$ was added and the mixture was again submitted to the sonic treatment. The mixture was kept at $4^{\circ} \mathrm{C}$ for $2 \mathrm{~h}$ and submitted to centrifugation at $12,400 \mathrm{~g}$ for $30 \mathrm{~min}$ at $4^{\circ} \mathrm{C}$. The supernatant was analyzed for protein content by the Lowry et al. (1951) method and stored in aliquots at $-70^{\circ} \mathrm{C}$, until used for WB.

Gel electrophoresis and electrophoretic transfer Saline antigen was diluted (v/v) in sample buffer, after boiling for $3 \mathrm{~min}$ at $98^{\circ} \mathrm{C}$. All preparations were submitted to electrophoresis in SDS-PAGE at 12\% under nonreducing conditions, as described by Laemmli (1970). After SDS-PAGE, the gels were either stained by Coomassie Brilliant Blue or transferred to nitrocellulose membranes $(0.45 \mu \mathrm{m}$, Sigma, US), as described by Towbin et al. (1979) using a transfer apparatus (Multiphor II, Pharmacia- LKB, US).

$W B$ - Preliminary experiments were carried out in order to determine the optimal conditions for WB, through block titration of the CSF, sera and conjugate. Nitrocellulose strips containing fractions of the saline antigen were blocked with 5\% non-fat milk in PBS-T for $2 \mathrm{~h}$ at room temperature and incubated overnight at $4^{\circ} \mathrm{C}$ with CSF samples diluted $1: 2$ or serum samples diluted 1:50 in 1\% non-fat milk in PBS-T (PBSTM). After washing with PBSTM, strips were incubated for $2 \mathrm{~h}$ at room temperature with the conjugate (peroxidase-labeled goat anti-human IgG, whole molecule, Sigma) diluted at 1:200 and 1:150 in PBSTM for CSF and serum samples, respectively. The strips were washed in PBS and developed with hydrogen peroxide and 3,3'diaminobenzidine tetra hydrochloride (Sigma) for $3 \mathrm{~min}$. The molecular weights of antigenic fragments were determined by comparison with high and low molecular markers (Sigma). The recognition of at least two immunodominant markers (molecular weight: 12, 13, 14, 18, $21,24,26-28,32,39,42,45,47,50,52,56,64-68,60-$ $75 \mathrm{kDa}$ ) of $T$. solium metacestodes was used as positivity criterion for WB, in CSF and serum samples, as described previously (Tsang et al. 1989, Simac et al. 1995, Shiguekawa et al. 2000, Barcelos et al. 2001).

Statistical analysis - Analysis of the data was performed using the Statistic for Windows Software (Stat. Soft, Inc. 1993). The sensitivity and specificity values for CSF or sera were determinated using binomial distribution. To compare the frequency of antigenic markers recognized in CSF and serum samples by WB, the percentages of the developed bands were tested by two proportions at the significance level of $5 \%$.

\section{RESULTS}

WB sensitivity for active NCC was 80 and $100 \%$ for CSF and serum, respectively, whereas for inactive NCC it was 0 and $30 \%$ for CSF and serum samples, respectively. On the other hand, WB specificity was $100 \%$ for both active and inactive NCC in either samples.

This present study, for the diagnosis of NCC by WB, found the bands in the interval of $12-70 \mathrm{kDa}$. Fig. 1 shows the peptides recognized in the CSF and serum samples of all analyzed groups. CSF samples from inactive NCC (G2) and control (G3) patients did not recognize any peptides in the total saline extract of $T$. solium metacestodes (Fig. 1A). Serum samples from active and inactive NCC and control patients reacted with peptides of apparent molecular weight of $80,86,95$, and $98 \mathrm{kDa}$ (Fig. 1B); this invalidates the use of such bands for diagnosis of NCC.

Fig. 2 shows the frequency of peptides recognized by IgG antibodies using WB in CSF and serum paired samples from patients with active NCC (Fig. 2A), inactive NCC (Fig. 2B), and controls (Fig. 2C). In the active NCC group (Fig. 2A), CSF samples recognized the 2832 and 39-42 kDa peptides in a significantly higher frequency than in the serum of the same patients $(p<0.05)$. The 47-52, 64-68, and $70 \mathrm{kDa}$ immunodominant peptides were detected in a higher frequency, both CSF and serum samples of active NCC (Fig. 2A) than in the inactive NCC $(p<0.05)$ (Fig. 2B), while in the control group (Fig. 2C) they were all negative. As shown in Fig. 2B and $2 \mathrm{C}$ the CSF samples of inactive NCC and control respectively were negative for all peptides. Although the $80,86,95$, and $98 \mathrm{kDa}$ bands were detected in the two first groups (CSF and serum samples, Fig. 2A and serum samples, Fig. 2B) they were found in the control group too, confirming their inespecificity, thus they were not considered in the analysis of frequencies the bands.

\section{DISCUSSION}

The immunological tests that detect parasite antigens in biological samples constitute the best choice to define which form of NCC, active or inactive, the patients present. However, they are expensive since monoclonal antibodies are employed, which makes such tests still unsuitable for routine laboratory applications, especially in developing countries (Schantz 2006). 


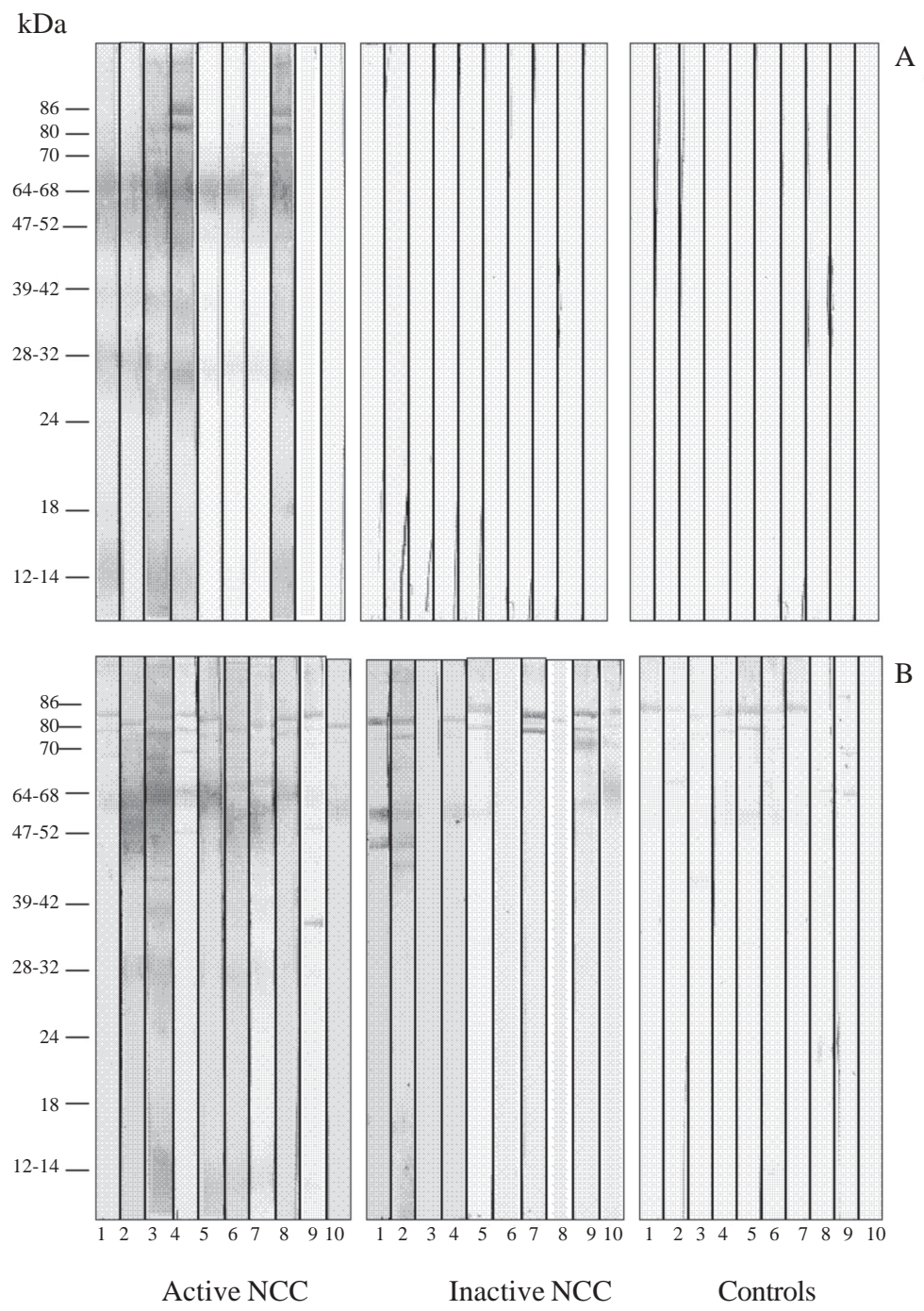

Fig. 1: western blot for the detection of IgG antibodies to Taenia solium metacestodes in cerebrospinal fluid (A) and serum (B) paired samples from patients with active neurocysticercosis (NCC) $(n=10)$, inactive NCC $(n=10)$, and 10 controls (with other neurological disorders).

The distinction between active and inactive-NCC is important for the diagnosis and treatment of the patients (White Jr 2000). Using excreted/secreted antigens of $T$. solium metacestode for ELISA tests, Molinari et al. (2002) showed that the CSF samples of active NCC patients had significantly higher positive indexes when compared to the inactive NCC patients. Using $T$. crassiceps antigens and CSF and serum paired samples from patients of NCC, Barcelos et al. (2005) showed the highest levels of specific $\operatorname{IgG}$ antibodies in both samples by ELISA, since the immune response is maximized when the parasite goes into degenerative phases.

In the present study the WB using total saline extract of $T$. solium metacestodes showed high sensitivity and specificity for the detection of specific bands $(\leq 70 \mathrm{kDa})$ in CSF and serum samples in the active NCC. These results may permit the differentiation of the active and inac- tive forms of NCC. Thus the sensitivity and specificity calcule depend on the classification of the NCC (active or inactive). Using purified glycoprotein antigens derived from T. solium cysticerci by EITB, the sensitivity and specificity were of 94 to $98 \%$ and approaching 100\% respectively, for patients with two or more cysts or enhancing lesions as demonstrated by others studies (Tsang et al. 1989, Garcia et al. 1991, Richards \& Schantz 1991).

The two CSF samples that did not recognize any peptide came from patients with only one colloidal vesicular cyst. These $20 \%$ negative results maybe explained by two reasons: (i) they were in the stages I and II described by Escobar et al. (1985) when the cysts are still alive without exposing their antigens; (ii) they had only one cyst, these results are in agreement with the study of Rajshekhar and Oommen (1997) that demonstrated sensitivity $<50 \%$ in patients with single intracranial cyst. 


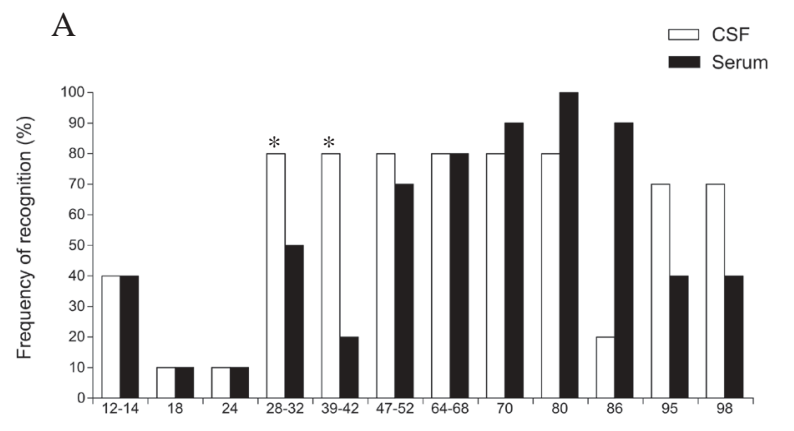

Peptides (kDa)
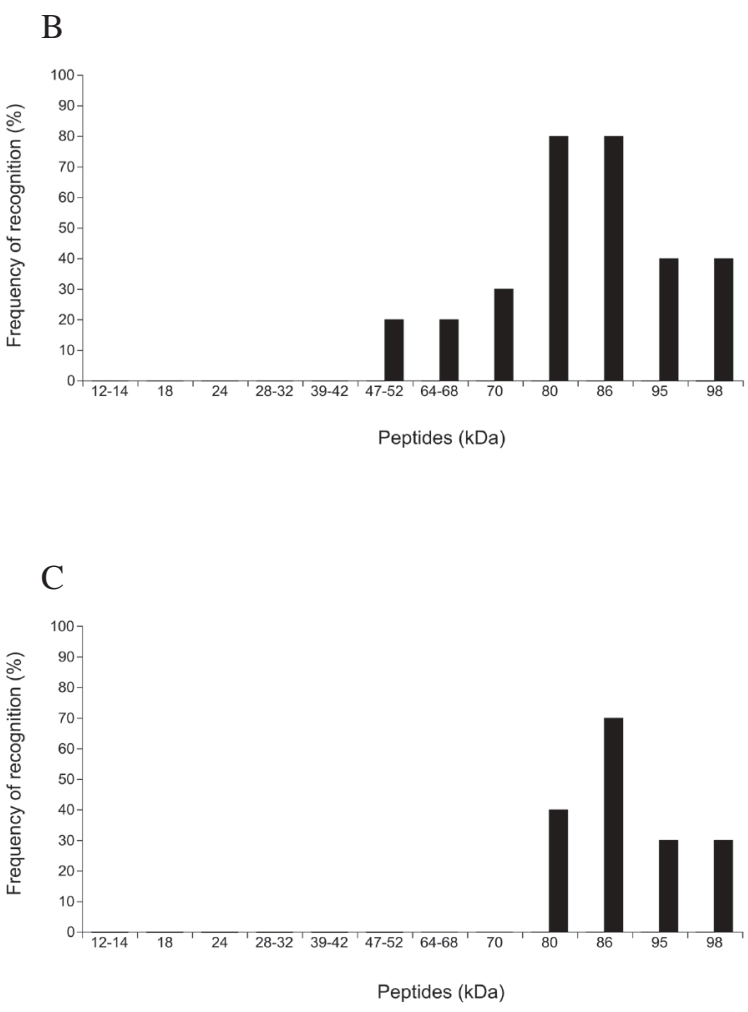

Fig. 2A: frequency of peptides recognized by $\mathrm{IgG}$ antibodies using western blot in cerebrospinal fluid (CSF) and serum paired samples from 10 patients with active neurocysticercosis (NCC); B: 10 patients with inactive NCC; C: 10 controls using total saline extract of Taenia solium metacestodes; $(*): p<0.05$.

The real interpretation of the results of these two patients is quite difficult since it is known that the presence or absence of antibodies in the CSF may depend on many other variables such as the individual immune response, the stage of cysts, the number of cysts, and the topography of the cyst. This particular last factor influences the result of the CSF examination in direct proportion to its proximity to the ventricular and/or subaracnoid space (Flisser et al. 1980, Sotelo \& Del Brutto 2000).

In the present study even using the total saline extract of $T$. solium metacestodes the WB identified six of the seven antigenic markers $(12,14,18,24,39-42$, and $50 \mathrm{kDa}$ ) with molecular weights similar to the glycoproteins described by Tsang et al. (1989) in the active NCC. The 28-32 kDa and 39-42 kDa peptides were only detected in the active NCC with a higher frequency in CSF samples than the serum samples. The finding of the $28 \mathrm{kDa}$ band with high specificity was described by Gottstein et al. (1987). The 47-52 and 64-68 kDa immunodominant peptides had high frequencies of detection in both samples of active NCC patients. Using saline extract of T. solium metacestodes, Barcelos et al. (2001) demonstrated that the markers of $64-68 \mathrm{kDa}$ were immunodominants in CSF samples, and Shiguekawa et al. (2000) found that the 47, 52, 64-68 kDa were immunodominants in serum samples. In this present study the $70 \mathrm{kDa}$ band was identified with 80 and $90 \%$ of recognition respectively in CSF and serum samples in the active NCC. In the inactive NCC the frequency of recognition of this band in serum samples was lower (30\%), than in the active NCC, with a statistical significance. Analyzing paired CSF and serum samples of NCC patients, Simac et al. (1995) showed in CSF samples an additional 60-75 kDa band and explained this frequent finding refering to a Miller et al. (1985) publication which considered the intrathecal secretion of specific antibodies responsible for such results.

The final conclusions were that the difference between active and inactive NCC may be done with the detection of peptides only in the CSF samples and that the 47-52, 64-68, and $70 \mathrm{kDa}$ bands may be included as specific markers for active NCC when detected in CSF samples by WB using total saline extract of $T$. solium metacestode.

\section{REFERENCES}

Alvarez JI, Colegial CH, Castaño CA, Trujillo J, Teale JM, Restrepo BI 2002. The human nervous tissue in proximity to granulomatous lesions induced by Taenia solium metacestodes displays an active response. J Neuroimmunol 127: 139-144.

Barcelos ISC, Ferreira MS, Moura LP, Biondi GF, Costa-Cruz JM 2005. Use of the paired samples (cerebrospinal fluid and serum) in immunodiagnostic of active and inactive human neurocysticercosis. Mem Inst Oswaldo Cruz 100: 427-429.

Barcelos ISC, Mineo JR, Silva DAO, Ferreira MS, Moura LP, Biondi GF, Costa-Cruz JM 2001. Detection of IgG in cerebrospinal fluid for diagnosis of neurocysticercosis: evaluation of saline and SDS extracts from Taenia solium and Taenia crassiceps metacestodes by ELISA and immunoblot assay. Trop Med Int Health 6: 219-226.

Carpio A 2002. Neurocysticercosis: an update. Lancet Infect Dis 2: 751-762.

Costa JM, Ferreira AW, Makino MM, Camargo ME 1982. Spinal fluid immunoenzymatic assay (ELISA) for neurocysticercosis. Rev Inst Med Trop São Paulo 24: 337-341.

Del Brutto OH 1999. Neurocisticercosis. Rev Neurol 29: 456-466.

Del Brutto OH, Rajshekhar V, White Jr AC, Tsang VCW, Nash TE, Takayanagui OM, Schantz PM, Evans CAW, Flisser A, Correa D, Botero D, Allan JC, Sarti E, Gonzalez AE, Gilman RH, Garcia HH 2001. Proposed diagnostic criteria for neurocysticercosis. Neurology 57: 177-183.

Escobar A, Aruffo C, Cruz-Sanchez F, Cervos-Navarro J 1985. 
Neuropathologic findings in neurocysticercosis. Arch Neurobiol 48:151-156.

Flisser A, Sarti E, Lightowlers M, Schantz P 2003. Neurocysticercosis: regional status, epidemiology, impact and control measures in the Americas. Acta Trop 87: 43-51.

Flisser A, Woodhouse E, Larralde C 1980. Human cysticercosis: antigens, antibodies and non-responders. Clin Exp Immunol 39: 27-37.

Garcia HH, Del Brutto OH, Nash TE, White Jr AC, Tsang VCW, Gilman RH 2005. New concepts in the diagnosis and management of neurocysticercosis (Taenia solium). Am J Trop Med Hyg 72: 3-9.

Garcia HH, Martinez M, Gilman R, Herrera G, Tsang VC, Pilcher JB, Diaz F, Verastegui M, Gallo C, Porras M 1991. Diagnosis of cysticercosis in endemic regions. The Cysticercosis Working Group in Peru. Lancet 338(8766): 549-551.

Gottstein B, Zini D, Schantz PM 1987. Species-specific immunodiagnosis of Taenia solium cysticercosis by ELISA and immunoblotting. Trop Med Parasitol 38: 299-303.

Laemmli UK 1970. Cleavage of structural proteins during the assembly of the head of bacteriophage T4. Nature 227: 680-685.

Lowry OH, Rosebrough NJ, Farr AL, Randall RJ 1951. Protein measurement with the Folin phenol reagent. $J$ Biol Chem 193: 265-275.

Machado LR, Livramento JA, Vaz AJ, Bueno EC, Mielli SR, Bastouly V, Nóbrega JPS 2002. IgG intrathecal synthesis and specific antibody index in patients with neurocysticercosis. Arq Neuropsiquiatr 60(2-B): 395-399.

Miller BL, Staugaitis SM, Tourtellotte WW, Shapshak P, Goldberg M, Heiner D, Weil M 1985. Intra-blood brain barrier IgG synthesis in cerebral cysticercosis. Arch Neurol 42: 782-784.

Molinari JL, Garcia-Mendoza E, de la Garza Y, Ramirez JA, Sotelo J, Tato P 2002. Discrimination between active and inactive neurocysticercosis by metacestode excretory/secretory antigens of Taenia solium in an enzyme-linked immunosorbent assay. Am J Trop Med Hyg 66: 777-781.

Montero E, González LM, Harrison LJS, Parkhouse RME, Gárate T 2003. Taenia solium cDNA sequence encoding a putative immunodiagnostic antigen for human cysticercosis. $J$
Chromatogr B Analyt Technol Biomed Life Sci 786: 255-269.

Rajshekhar V, Oommen A 1997. Serological studies using ELISA and EITB in patients with solitary cysticercus granuloma and seizures. Neurol Infect Epidemiol 2: 177-180.

Reiber H, Felgenhauer K 1987. Protein transfer at the blood cerebrospinal fluid barrier and the quantification of the humoral immune response within central nervous system. Clin Chim Acta 163: 319-328.

Richards Jr F, Schantz PM. 1991. Laboratory diagnosis of cysticercosis. Clin Lab Med 11: 1011-1028.

Salgado P, Rojas R, Sotelo J 1997. Cysticercosis. Clinical classification based on imaging studies. Arch Intern Med 157: 1991-1997.

Schantz PM 2006. Progress in diagnosis, treatment and elimination of echinococcosis and cysticercosis. Parasitol Int 55 (Suppl.): 7-13.

Shiguekawa KYM, Mineo JR, Moura LP, Costa-Cruz JM 2000. ELISA and western blotting tests in the detection of $\mathrm{IgG}$ antibodies to Taenia solium metacestodes in serum samples in human neurocysticercosis. Trop Med Int Health 5: 443-449.

Simac C, Michel P, Andriantsimahavandy A, Esterre P, Michault A 1995. Use of enzyme-linked immunosorbent assay and enzyme-linked immunoelectrotransfer blot for the diagnosis and monitoring of neurocysticercosis. Parasitol Res 81: 132-136.

Sotelo J, Del Brutto, OH 2000. Brain cysticercosis. Arch Med Res 31: 3-14.

Sotelo J, Guerrero V, Rubio F 1985. Neurocysticercosis: a new classification based on active and inactive forms. A study of 753 cases. Arch Intern Med 145: 442-445.

Towbin H, Staehelin T, Gordon J 1979. Electrophoretic transfer of proteins from polyacrylamide gels to nitrocellulose sheets: procedure and some applications. Proc Natl Acad Sci USA 76: 4350-4354.

Tsang VCW, Brand JA, Boyer AE 1989. An enzyme-linked immunoelectrotransfer blot assay and glycoprotein antigens for diagnosing human cysticercosis (Taenia solium). J Infect Dis 159: 50-59.

White Jr AC 2000. Neurocysticercosis: updates on epidemiology, pathogenesis, diagnosis and management. Ann Rev Med 51: 187-206. 
